\title{
DESENVOLVIMENTO DE FILMES BIODEGRADÁVEIS DE QUITOSANA INCORPORADOS COM ÓLEO ESSENCIAL
}

Isabella Pelosi Borges de Deus - isabella_pelosi@hotmail.com Instituto Federal Goiano, Campus Rio Verde.

Josemar Gonçalves de Oliveira Filho- Josemar.gooliver@ gmail.com Instituto Federal Goiano, Campus Rio Verde.

Anna Carolina Valadares Fernandes - carol_valadares06@ hotmail.com Instituto Federal Goiano, Campus Rio Verde.

Cassia Cristina Alves Fernandes - cassiacefetrv@gmail.com Instituto Federal Goiano, Campus Rio Verde.

Mariana Buranelo Egea - mariana.egeia@ifgoiano.edu.br Instituto Federal Goiano, Campus Rio Verde. 


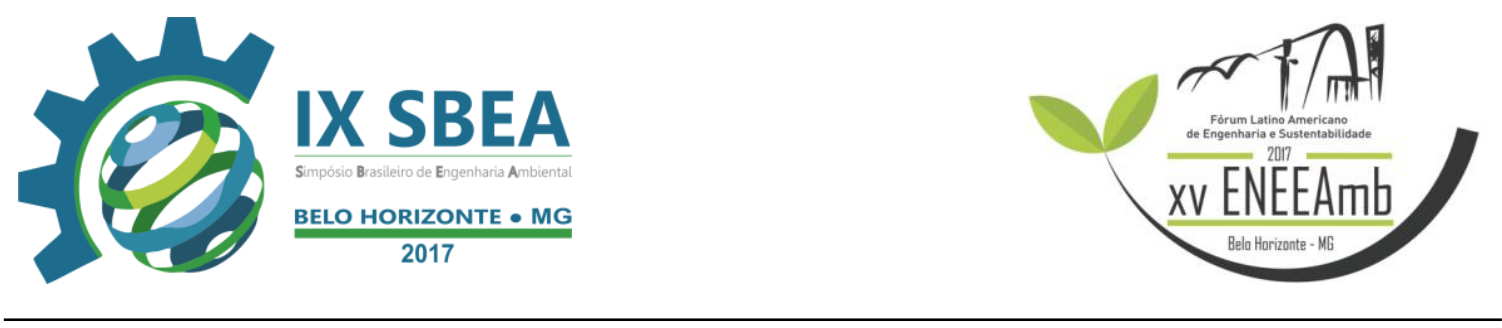

\section{RESUMO}

Nos últimos anos, tem havido um reconhecimento de vários setores da sociedade sobre a necessidade de se reduzir a quantidade de materiais plásticos descartados no meio ambiente. Neste sentido, existe a necessidade de estudos para o desenvolvimento de embalagens de fácil degradação e que não sejam prejudiciais ao meio ambiente. Desta forma, objetivou-se desenvolver e caracterizar filmes biodegradáveis de quitosana incorporados com o óleo essencial extraído das folhas de Citrus limonia. Os filmes foram produzidos pela técnica casting utilizando a concentração de $2 \%(\mathrm{p} / \mathrm{v})$ de quitosana e concentrações finais do óleo essencial de Citrus limonia de 0 a $1 \%$ (v/v). Os filmes foram caracterizados quanto ao teor de umidade, espessura, permeabilidade ao vapor de água e biodegradabilidade. A incorporação do óleo essencial aumentou a espessura dos filmes na concentração de $1 \%$ e reduziu o teor de umidade e a permeabilidade a vapor de água a partir da concentração de 0,25. Desta forma, concluise que os filmes desenvolvidos apresentam potencial para aplicações como embalagens biodegradáveis e ativas.

Palavras-chave: Embalagens, Biodegradabilidade, Inovação.

\section{INTRODUÇÃO/OBJETIVO}

Os polímeros de origem petroquímica são largamente utilizados em embalagens alimentícias. Sua ampla utilização relaciona-se com suas vantagens em relação a outros materiais, pois são química e mecanicamente resistentes, leves, possuem propriedades de barreira ao oxigênio e a compostos aromáticos e podem ser termossoldados ou impressos, além de apresentarem baixo custo. Por outro lado, estes polímeros apresentam baixa permeabilidade ao vapor d'água e são considerados não biodegradáveis (THARANATHAN, 2003), de forma que permanecem praticamente intactos ao longo dos anos e acarretam em sérios problemas ecológicos e ambientais (DO SUL, COSTA, 2014).

A dificuldade de reciclagem da maioria das embalagens sintéticas disponíveis tem incentivado pesquisas nacionais e internacionais no sentido de incrementar e/ou desenvolver materiais biodegradáveis com características que permitam a sua utilização 


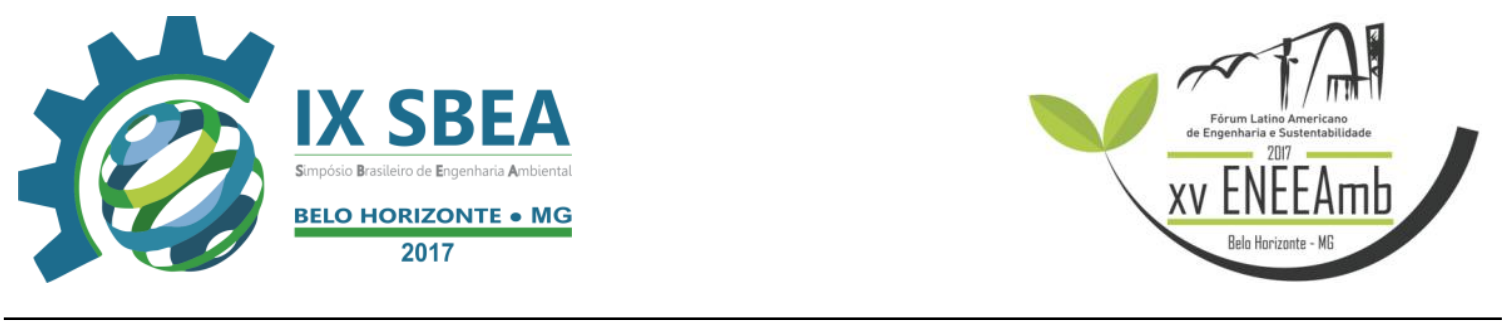

em embalagens (MALI; GROSSMANN; YAMASHITA, 2010). Com isso, a utilização de polímeros biodegradáveis a partir de fontes renováveis torna-se uma alternativa, pois podem passar pelo processo de compostagem, que é um processo de deterioração de resíduos por biodegradação, e é considerada a rota mais segura para tratamento de resíduos de embalagens biodegradáveis (DAVIS; SONG, 2006).

Quitosana é um polissacarídeo catiônico derivado da quitina presente em cascas de camarão, caranguejo e insetos, é insolúvel em água e o segundo polímero natural mais abundante (LI et al., 2010) e por isso pode ser utilizada para formar filmes (BEVERLYA et al., 2008). Filmes a base de quitosana apresentam propriedades de barreira moderada ao oxigênio, boas propriedades de barreira ao dióxido de carbono, mas alta permeabilidade ao vapor de água, devido à sua natureza hidrofílica (SÁNCHEZ-GONZÁLEZ et al., 2010) o que limita a sua utilização.

Quando se adiciona um componente hidrofóbico à suspensão formadora do filme, produzem-se filmes compostos, nos quais o componente lipídico atua como barreira ao vapor de água, e a proteína ou polissacarídeo fornecem a barreira ao oxigênio e as características mecânicas necessárias a um bom filme (ANKER, STADING, HERMANSSON, 2001). Uma opção seria a incorporação de óleos essenciais (OEs) à matriz polimérica utilizada para a produção dos filmes, com o intuito de promover uma melhoria nas propriedades de barreia a umidade e proteção antimicrobiana e antioxidante ao alimento em questão.

Os óleos essenciais são substâncias lipídicas naturais de origem vegetal voláteis classificados como GRAS (Generally Regarded As Safe), o que os torna atrativos ao consumidor por não apresentarem efeito tóxico e apresentarem atividades antioxidantes, antimicrobianas e outras (PEREIRA et al., 2006).

A espécie Citrus limonia Osbeck é um fruto originário da Índia conhecida como limão china, limão rosa ou limão vinagre. Essa espécie é cultivada em pomares e viveiros, possuindo como vantagem a indução da maturação precoce das frutas, proporcionando melhores preços no início de safra e ainda pode ser usado como porta enxerto (REDA et al., 2006). Não há relatos na literatura sobre o estudo com óleo essencial das folhas desta espécie para incorporação em filmes biodegradáveis. 


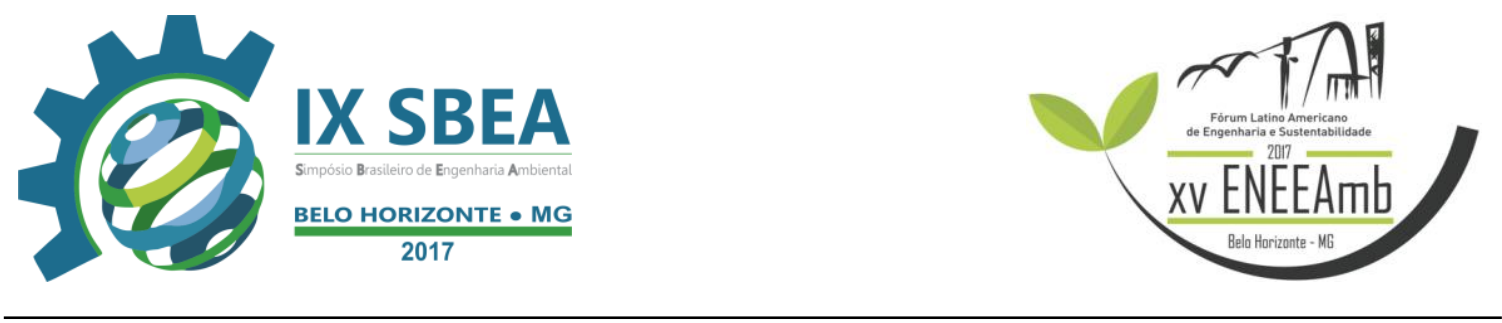

Neste contexto, objetivou-se desenvolver e caracterizar filmes biodegradáveis de quitosana incorporados com o óleo essencial extraído das folhas de Citrus limonia.

\section{METODOLOGIA}

\section{Produção dos filmes}

Os filmes à base de quitosana foram produzidas de acordo com método descrito por Ojagh et al. (2010) com algumas modificações. As soluções de quitosana formadoras de filme foram preparadas dissolvendo $2 \%(\mathrm{p} / \mathrm{v})$ de quitosana e uma solução aquosa de $\mathrm{H}_{2} \mathrm{O}(1 \%(\mathrm{v} / \mathrm{v}))$ de ácido acético glacial sob agitação em uma placa de agitação magnética a $50{ }^{\circ} \mathrm{C}$. Filtrou-se a solução de quitosana resultante através de um filtro de papel Whatman, seguida de filtração sob vácuo para eliminar quaisquer partículas não dissolvidas. Após filtração, a solução foi retornada para o agitador magnético e adicionou-se glicerol $(50 \%, \mathrm{~m} / \mathrm{v})$ e misturou-se durante $30 \mathrm{~min}$. Adicionouse $0,2 \%(\mathrm{v} / \mathrm{v})$ de Tween 80 ao óleo essencial como um emulsionante para facilitar a sua dispersão na solução de formação de filme e após 15 minutos de agitação, homogeneizou-se o óleo essencial de Citrus limonia à solução de quitosana para atingir concentrações finais de $0 \%$ a $1 \%(\mathrm{v} / \mathrm{v})$. As soluções filmogênicas foram vertidas em placas de Petri de 150 x 20mm e levadas para estufa com circulação de ar por 48 h a 45 ${ }^{\circ} \mathrm{C}$. Após a secagem os filmes foram retirados das placas e acondicionados em dessecadores até as análises.

\section{Espessura}

As espessuras dos filmes foram aferidas com o auxílio de um micrômetro em cinco pontos de cada filme escolhidos aleatoriamente e calculou-se a média em $\mathrm{mm}$ (ALMEIDA et al., 2013).

\section{Determinação da umidade}

A determinação da umidade do biofilme foi realizada em triplicata, onde as amostras de biofilme de $4 \mathrm{~cm}^{2}$ foram previamente pesadas e inseridas em estufa a $105^{\circ} \mathrm{C}$ por 24 horas (STANDER METHODOS, 1967). 


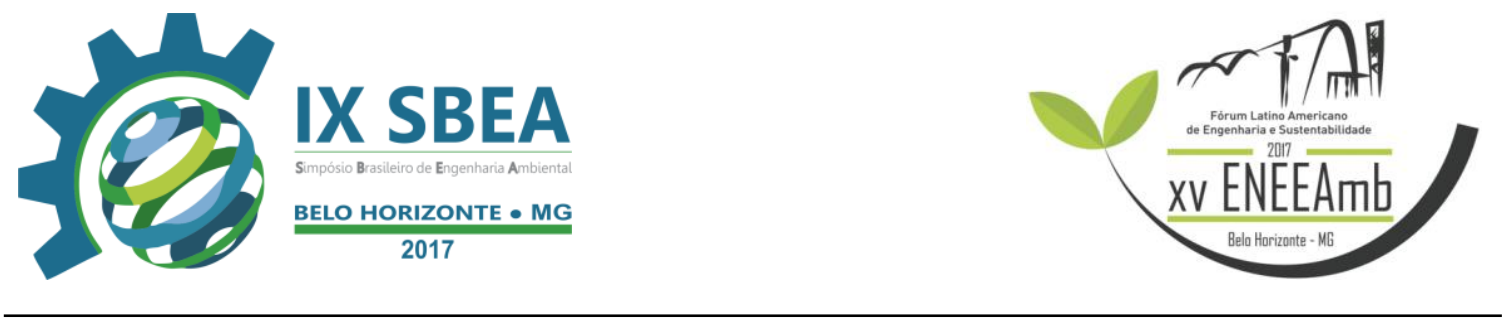

\section{Permeabilidade ao vapor d'água}

A permeabilidade dos filmes ao vapor d'água foi determinada segundo Lopes et al. (2014), onde, $50 \mathrm{~cm}^{2}$ de filme, em triplicata, foram colocados em dessecadores com solução saturada de $\mathrm{NaCl}(75 \% \mathrm{UR})$ à $25^{\circ} \mathrm{C}$. As amostras foram pesadas durante três dias, sendo que no primeiro dia, dela foi realizada de 2 em 2 horas, nas 6 primeiras horas e, após isso, as pesagens foram realizados com intervalos de 24 horas. A permeabilidade foi determinada pela declividade da curva resultante da plotagem massa pelo tempo e expressa em g.m $\mathrm{m}^{-2} \mathrm{dia}^{-1}$.

\section{RESULTADOS E DISCUSSÃO}

A Tabela 1 apresenta os resultados das análises de espessura, umidade, permeabilidade ao vapor de água dos filmes de quitosana incorporados com o óleo essencial de Citrus limonia.

A técnica de casting utilizada no desenvolvimento dos filmes permitiu um controle satisfatório da espessura, onde elas variaram de $0,17 \mathrm{~mm}$ a $0,28 \mathrm{~mm}$, sem diferença significativa até a concentração de $0,75 \%$ de óleo essencial.

Tabela 1- Médias ( \pm desvio padrão) das análises de caracterização dos filmes de quitosana incorporados com óleo essencial de Citrus limonia.

\begin{tabular}{|c|c|c|c|}
\hline Tratamento & Espessura (mm) & Umidade (\%) & $\begin{array}{l}\text { Permeabilidade ao vapor } \\
\text { d'água }\left(\mathrm{g} \cdot \mathrm{m}^{-2} \text { dia }^{-1}\right)\end{array}$ \\
\hline Controle absoluto* & $0,19 \pm 0,04^{b}$ & $24,20 \pm 0,31^{\mathrm{a}}$ & $339,36 \pm 3,63^{\mathrm{a}}$ \\
\hline Controle* & $0,17 \pm 0,04^{\mathrm{b}}$ & $24,80 \pm 0,34^{\mathrm{a}}$ & $320,64 \pm 9,35^{\mathrm{a}}$ \\
\hline $0,25 \%$ & $0,18 \pm 0,03^{b}$ & $23,00 \pm 0,65^{\mathrm{bc}}$ & $341,07 \pm 6,52^{b}$ \\
\hline $0,50 \%$ & $0,19 \pm 0,06^{\mathrm{b}}$ & $23,12 \pm 0,48^{\mathrm{bc}}$ & $307,52 \pm 16,09^{b}$ \\
\hline $0,75 \%$ & $0,23 \pm 0,03^{\mathrm{ab}}$ & $23,81 \pm 0,40^{\mathrm{ab}}$ & $279,92 \pm 5,73^{\mathrm{c}}$ \\
\hline $1 \%$ & $0,28 \pm 0,05^{\mathrm{a}}$ & $21,88 \pm 0,30^{\mathrm{c}}$ & $277,2 \pm 8,73^{\mathrm{c}}$ \\
\hline
\end{tabular}

*Controle absoluto (filme sem óleo essencial e sem tween 80) e controle (filme com tween 80 e sem óleo essencial). *Médias na mesma coluna com diferentes sobrescritos diferem significativamente a $\mathrm{p} \leq 0,05$ de acordo com o teste de Tukey.

Bertan et al. (2005) observaram que a adição de substâncias hidrofóbicas aumentaram a espessura dos filmes, e por isso, são utilizadas alíquotas diferentes para 
cada formulação. Neste trabalho, pode-se considerar que a porcentagem de óleo essencial (substância hidrofóbica) a partir $0,75 \%$ modificou esta espessura.

As espessuras encontradas neste estudo foram superiores comparados aos resultados relatados por Liu et al. (2014) $(28,1 \pm 1,1$ a $28,7 \pm 1,1 \mu \mathrm{m})$ e Peng e Li (2014) $(77,0 \pm 7,0$ a 105,0 $\pm 2,0 \mu \mathrm{m})$ para filme de quitosana.

Além disso, essas diferenças de espessuras dos filmes de quitosana se justificam pelo fato de que as condições de preparo dos filmes nem sempre são as mesmas, dentre as quais, pode-se citar a concentração da solução de quitosana, volume de solução e amostras de quitosana com diferentes massas molares (FRAGUAS et al., 2015).

Com relação a umidade, observou-se que os filmes controle e controle absoluto (sem diferença estatística) apresentaram os maiores valores de umidade, 24,20 e $24,80 \%$, respectivamente. Observou-se que a incorporação do óleo essencial nas concentrações de 0,25 a $1 \%$ reduziu de forma significativa a umidade dos filmes, sendo que esta última concentração apresentou o menor valor de umidade $21,88 \%$, diferindo dos demais tratamentos.

Segundo Park e Zhao (2004), quando se faz a incorporação de óleo essencial em filmes de quitosana ocorre a formação de ligações covalentes entre os grupos funcionais de cadeias da quitosana e do óleo essencial, levando a uma diminuição na disponibilidade de grupos hidroxila e amino, limitando as interações polissacarídeoágua por ligação de hidrogênio e resultando em uma diminuição do teor de umidade dos filmes.

Quanto a taxa de permeabilidade ao vapor de água observou-se que, conforme a concentração de óleo essencial de $C$. limonia aumentou, houve uma diminuição na taxa de permeabilidade ao vapor de água. Jahed e colaboradores (2017), também observaram uma diminuição significativa na taxa de permeabilidade ao vapor de água quando incorporaram óleo essencial de Carum copticum em filmes de quitosana.

O filme de quitosana associado a óleo essencial apresenta baixas propriedades hidrofílicas justamente por causa do aumento das ligações de hidrogênio entre os grupos funcionais da matriz de quitosana e os grupos hidroxila dos óleos essenciais e do glicerol. A natureza lipídica dos óleos essenciais também contribui para o decréscimo da taxa de permeabilidade ao vapor de água (OJAGH et al. 2010). 


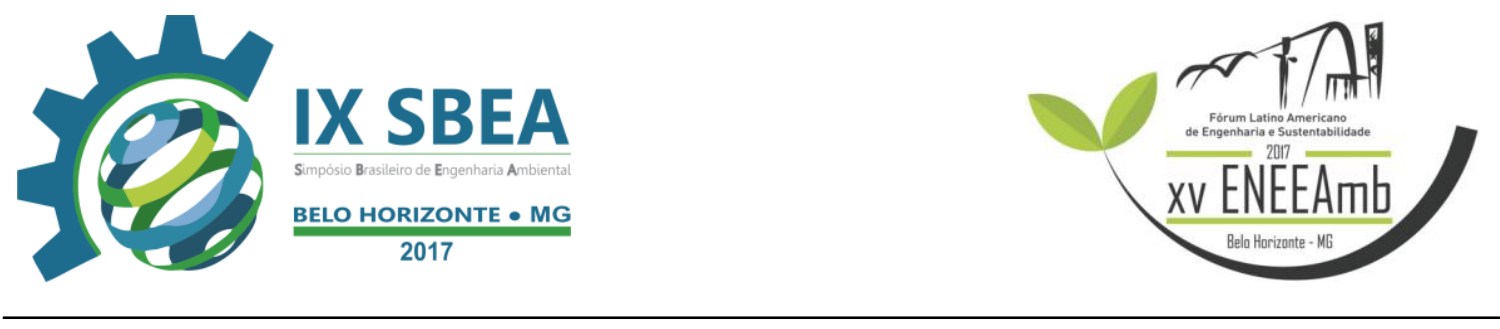

\section{CONCLUSÕES/RECOMENDAÇÕES}

Em função dos resultados obtidos neste trabalho pode-se concluir que a incorporação do óleo essencial de $C$. limonia em filmes de quitosana na concentração de $1 \%$ aumenta a espessura dos filmes e a partir da concentração de $0,25 \%$ reduz o teor de umidade e melhora as propriedades de barreira reduzindo a taxa de permeabilidade ao vapor de água. Portanto, os filmes desenvolvidos apresentam potencial para possíveis aplicações como embalagens biodegradáveis.

\section{REFERÊNCIAS BIBLIOGRÁFICAS}

ANKER, M.; STADING, M.; HERMANSSON, A. Aging of whey protein films and the effect on mechanical and barrier properties. Journal of Agricultural and Food Chemistry, v. 49, n. 2, p. 989-995, 2001.

BERTAN, L. C.; TANADA-PALMU, P. S.; SIANI, A. C.; GROSSO, C. R. F. Effect of fatty acids and "Brazilian elemi" on composite films base don gelatin. Food Hydrocolloids, v. 19, n. 1, p. 73-82, 2005.

BEVERLYA，R. L.; JANES M.E.; PRINYAWIWATKUL W.; NO H. K. Edible chitosan films on ready-to-eat roast beef for the control of Listeria monocytogenes. Food Microbiology, v. 25, n. 3, p. 534-537, 2008.

DAVIS, G.; SONG, J. H. Biodegradable packaging based on raw materials from crops and their impact on waste management. Industrial Crops and Products, v. 23, p. 147161, 2006.

DO SUL, J. A. I.; COSTA, M. F. The present and future of microplastic pollution in the marine environment. Environmental Pollution, v. 185, p. 352-364, 2014.

FRAGUAS, R. M; SIMÃO, A. A.; FARIA, P. V.; QUEIROZ E. R.; OLIVEIRA JÚNIOR, Ê. N.; ABREU, C. M. P. Preparo e caracterização de filmes comestíveis de quitosana. Polímeros, v. 25, p. 48-53, 2015.

JAHED, E.; KHALEDABAD, M. A.; ALMASI, H.; HASANZADEH ,R. Physicochemical properties of Carum copticum essential oil loaded chitosan films containing organic nanoreinforcements. Carbohydrate Polymers, v. 164, p. 325-338, 2017. 
LI, Y.; GUOA, X.; LINA, P.; FANA, C.; SONGA, Y. Preparation and functional properties of blend films of gliadins and chitosan. Carbohydrate Polymers, v. 81, n. 2, p. 484-490, 2010.

LIU, M.; ZHOU, Y.; ZHANG, Y.; YU, C.; CAO, S. Physicochemical, mechanical and thermal properties of chitosan films with and without sorbitol. International Journal of Biological Macromolecules, v. 70, p. 340-346, 2014.

MALI, S.; GROSSMANN, M. V. E.; YAMASHITA, F. Filmes de amido: produção, propriedades e potencial de utilização. Semina: Ciências Agrárias, v. 31, n. 1, p. $137-$ $156,2010$.

MARTUCCI, J. F.; RUSECKAITE, R. A. Biodegradation of three-layer laminate films based on gelatin under indoor soil conditions. Polymer Degradation and Stability, v. 94, n. 8, p. 1307-1313, 2009.

OJAGH, S. M. Development and evaluation of a novel biodegradable film made from chitosan and cinnamon essential oil with low affinity toward water. Food Chemistry, v. 122, n. 1, p. 161-166, 2010.

PARK, S. I.; ZHAO Y. Incorporation of a high concentration of mineral or vitamin into chitosan-based films. Journal of Agricultural and Food Chemistry, v. 52, p. 19331939, 2004.

PENG, Y.; LI, Y. Combined effects of two kinds of essential oils on physical, mechanical and structural properties of chitosan films. Food Hydrocolloids, v. 36, p. 287-293, 2014.

PEREIRA, M.C.; VILELA, G.R. COSTA, L.M.A.S.; SILVA, R.F.; FERNANDES, A.F.; FONSECA, E.W.N.; PICOLLI, R.H. Inibição do desenvolvimento fúngico através da utilização de óleos essenciais de condimentos. Ciências e Agrotecnologia, v. 30, n. 4, p. 731-738, 2006.

SÁNCHEZ-GONZÁLEZ, L.; CHÁFER, M.; AMPARO C.; GONZÁLEZ-MARTÍNEZ. Physical properties of edible chitosan films containing bergamot essential oil and their inhibitory action on Penicillium italicum. Carbohydrate Polymers, Barking, v. 82, n. 2, p. $277-283,2010$. 
THARANATHAN, R. N. Biodegradable films and composite coatings: past, present and future. Trends in Food Science and Technology, v.14, p.71-78, 2003. 